\title{
Impact of Estradiol Monitoring on the Prediction of Intrauterine Insemination Outcome
}

\author{
Remzi Atilgan, Mustafa Ekinci, Ekrem Sapmaz, Zehra Sema Ozkan
}

\begin{abstract}
Purpose: To evaluate the predictive value of estradiol levels on the day of human chorionic gonadotropin (hCG) administration on intrauterine insemination success rate.
\end{abstract}

Materials and methods: The present study included 200 intrauterine insemination (IUI) cycles performed between J une 2011 and O ctober 2012. All IUI cycles were preceded by ovarian stimulation with gonadotropins starting on cycle day 3 . A single IUI was performed 24 to 36 hours after hCG administration. Binary logistic regression analysis was performed to define the covariates of IUI success. The main outcome measure, the clinical pregnancy rate per cycle, was assessed according to the estradiol level.

Results: With $L R \pm 2$ and $A \cup C=0.73, R O C$ analysis revealed out the estradiol level as $465 \mathrm{pg} / \mathrm{ml}$ to predict the pregnancy with $60 \%$ sensitivity and $66 \%$ specificity. Binary logistic regression analysis identified the presence of estradiol levels higher than $465 \mathrm{pg} / \mathrm{ml}(\mathrm{p}<0.01,95 \% \mathrm{Cl}=0.147-0.687)$ and stimulation duration $(p<0.01,95 \% \mathrm{Cl}=0.201-0.705)$ as the covariates approached statistical significance for IUI success.

Conclusion: Estradiol level $>465 \mathrm{pg} / \mathrm{ml}$ on the day of $\mathrm{hCG}$ administration might point out advanced outcome on mild ovarian stimulation combined with insemination.

Keywords: Intrauterine insemination, Pregnancy rate, Estradiol level, Outcome.

How to cite this article: Atilgan R, Ekinci M, Sapmaz E, Ozkan ZS. Impact of Estradiol Monitoring on the Prediction of Intrauterine Insemination Outcome. Int J Infertility Fetal Med 2013;4(3):88-92.

\section{Source of support: Nil}

\section{Conflict of interest: None}

\section{INTRODUCTION}

Intrauterine insemination (IUI) is widely used treatment modality for unexplained infertility and male subfertility. It is generally considered to be an intermediate step modality before the application of assisted reproductive technologies (ART) such as in vitro fertilization with or without intracytoplasmic sperm injection. ${ }^{1}$ The success rate of IU I still has controversy and approximately 10 to $20 \%$ clinical pregnancy rate (CPR) is expected per cycle., ${ }^{2,3} \mathrm{IU}$ I combined with controlled ovarian stimulation (COS) may approach the cumulative pregnancy rate of $A R T$ in unexplained

Date of Received: 20-12-2012

Date of Acceptance: 03-12-2013

Date of Publication: September 2013 infertility and male subfertility. ${ }^{4}$ L ow CPRs seen in COS/ IUI are often attributed to the use of mild stimulation protocols aiming for a monofollicular response. ${ }^{5} \mathrm{~A}$ ggressive protocols using higher dose of gonadotrophins improves pregnancy rates by increasing the number of preovulatory follicles and the rate of multiple pregnancy. ${ }^{6}$ In our study we aimed to investigate a cut-off value for estradiol level to predict the insemination outcome when performed with mild ovarian stimulation.

\section{MATERIALS AND METHODS}

The study population was consisted of 200 ovulation induction cycle proceeded with IUI between J une 2011 and 0 ctober 2012. The inclusion criteria were failure to conceive for $\geq 12$ months of unprotected intercourse, female age $<38$ years, basal follicle-stimulating hormone (FSH) levels $<12 \mathrm{IU} / \mathrm{l}$, and total motile sperm count $>5$ million. The exclusion criteria were ovarian cysts $>15 \mathrm{~mm}$ on the baseline transvaginal ultrasound scan, severe endometriosis (according to the revised A merican Fertility Society stage III and IV), total number of motile sperm $<5$ million, any contraindication for 1 of the ovarian stimulation drugs and multiple pregnancy.

All couples had undergone a standard infertility evaluation thatincluded medical history, physical examination, assessment of tubal patency by either hysterosal pingography or laparoscopy, basal FSH, LH, E2, TSH, PRL evaluation on cycle day 3 and a semen analysis. A bnormal semen analysis results were confirmed by a second analysis $\geq 3$ weeks apart. Semen samples with a concentration of $>20$ million $/ \mathrm{ml}$, progressive motility $>50 \%$, and normal morphology $>14 \%$ were considered normal. ${ }^{7,8}$ The motility categories were classified as grade A (rapid-linear plus sluggish progressive motility), grade $B$ (nonprogressive motility), and grade $C$ (immotility). A semen analysis failing to meet these criteria but with a TM SC of $>5$ million were included to IUI cycle. Couples were considered eligible if the woman had at least one patent fallopian tube and had a documented normal endometrial cavity.

A transvaginal ultrasound scan was performed on cycle day 3. W omen with ovarian cysts $>15 \mathrm{~mm}$ were excluded. Ovarian stimulation was performed with recombinant FSH (rFSH; Gonal-F, M erck Serono, Istanbul, Turkey or 
Puregon, MSD, Istanbul, Turkey) with a starting dose of $75 \mathrm{IU} /$ day (body mass index $<25 \mathrm{~kg} / \mathrm{m}^{2}$ ) and $100 \mathrm{IU} /$ day (body mass index $\geq 25 \mathrm{~kg} / \mathrm{m}^{2}$ ). The rFSH injections began on cycle day 3. The first scan was done on the seventh day of gonadotropin stimulation, and the rFSH dose was adjusted according to the ovarian response. The ovarian response and endometrial thickness were strictly monitored by transvaginal ultrasonography. When the average diameter of the leading follicle reached $\geq 16 \mathrm{~mm}, 250 \mathrm{mcg}$ of recombinant human chorionic gonadotropin (hCG, Ovitrelle, M erck Serono and Istanbul, Turkey) was administered. The endometrial thickness and estradiol levels on the day of hCG administration was evaluated. A single IUI was performed 24 to 36 hours after hCG injection. The semen samples used for insemination were processed within 1 hour after ejaculation, using density gradient centrifugation, followed by washing with culture medium. W omen had bed rest for 15 minutes after IUI. Luteal phase support was given all women with $90 \mathrm{mg}$ daily vaginal micronized $8 \%$ progesterone gel. When there were $\geq 4$ follicle with a diameter $\geq 16 \mathrm{~mm}$ or the serum estradiol levels were higher than $1500 \mathrm{pg} / \mathrm{ml}$, hCG administration was canceled and regular coitus were interdicted to prevent multiple pregnancy.

\section{STATISTICAL ANALYSIS}

Statistical analysis was performed by statistical package for social sciences (SPSS) version 16.0 (Inc, Chicago, Illinois, USA). The main outcome measurement was CPR per cycle. Clinical pregnancy was defined as evidence of pregnancy by ultrasound examination of the gestational sac at weeks 5 to 7 . To predict the outcome, female age, duration of infertility, baseline FSH level, baseline LH level, baseline estradiol level, total rFSH dose, stimulation duration and TMSC were included in the calculations. Descriptive statistics were presented as percentages or the mean \pm standard deviation. Differences between groups for categorical variables were analyzed using the Chi-square test or Fisher's exact test, as appropriate, and comparisons of continuous variables between groups were analyzed using Student's t-test according to the results of their normality tests. B inary logistic regression analysis was employed on estradiol level on hCG day, dominant follicle count, stimulation duration, total motile sperm count before and after washing, BMI, previous pelvic surgery and insemination time to identify the significant covariates with IUI success. ROC analysis was performed to determine the area under curve and $L R+$ (likelihood ratio) value of estradiol level for predicting pregnancy. $p$-value $<0.05$ was considered as statistically significant.

\section{RESULTS}

A total of 206 couples diagnosed with infertility were included this study. The overall CPR of the cohort was 16.8\% per cycle. The demographic and clinical characteristics of women were presented in Table 1. Stimulation and insemination parameters of couples were presented in Table 2. With $L R+=2$ and $A \cup C=0.73, R O C$ analysis revealed out the estradiol level as $465 \mathrm{pg} / \mathrm{ml}$ to predict the pregnancy with $60 \%$ sensitivity and $66 \%$ spesifity. We compared the ovarian stimulation and insemination parameters of couples according to estradiol level $<465 \mathrm{pg} / \mathrm{ml}$ and $>465 \mathrm{pg} / \mathrm{ml}$. The comparison revealed out significant difference for parameters of dominant follicle count $(1.1 \pm 0.3$ vs $2.3 \pm 0.9, p<0.01)$ and CPR $(12.4 \%$ vs

\begin{tabular}{|c|c|}
\hline Age (years) & $29.3 \pm 4.9$ \\
\hline Infertility duration (months) & $53.9 \pm 41$ \\
\hline \multicolumn{2}{|l|}{ Infertility type } \\
\hline - Primary & $145(69.7 \%)$ \\
\hline - Secondary & $63(30.3 \%)$ \\
\hline Body mass index $\left(\mathrm{kg} / \mathrm{m}^{2}\right)$ & $24.8 \pm 4.3$ \\
\hline Day 3 FSH (IU/ml) & $6.2 \pm 3.5$ \\
\hline Day 3 LH (IU/ml) & $5.7 \pm 4.2$ \\
\hline Day $3 \mathrm{E}_{2}(\mathrm{IU} / \mathrm{ml})$ & $54.2 \pm 37.1$ \\
\hline Prolactin IU/ml) & $13.3 \pm 8.3$ \\
\hline TSH* (IU/ml) & $1.7 \pm 3.1$ \\
\hline \multicolumn{2}{|l|}{ Ovarian reserve } \\
\hline$-\quad \mathrm{AFC} * * 10$ & $107(51.4 \%)$ \\
\hline$-A F C=10-20$ & $43(20.7 \%)$ \\
\hline$-\quad A F C>20$ & $58(27.9 \%)$ \\
\hline \multicolumn{2}{|l|}{ Menstrual cycle } \\
\hline - Regular & $152(73.1 \%)$ \\
\hline - Oligomenorrhea & $51(24.5 \%)$ \\
\hline - Menometrorrhagia & $5(2.4 \%)$ \\
\hline \multicolumn{2}{|l|}{ Tubal patency } \\
\hline - Unilateral & $25(12 \%)$ \\
\hline - Bilateral & $181(88 \%)$ \\
\hline
\end{tabular}

Note: Values are presented as mean \pm SD or number and percentage where applicable; *Tyhroid stimulating hormone; **Antral follicle count

Table 2: Ovarian stimulation and insemination characteristics of couples

$\begin{array}{ll}\text { Gonadotrophin start dose (IU) } & 99 \pm 64 \\ \text { Gonadotrophin final dose (IU) } & 105 \pm 60 \\ \text { Total gonadotropin dose (IU) } & 905 \pm 567 \\ \text { Stimulation duration (days) } & 9.4 \pm 3.6 \\ \text { TMSC* }\left(\times 10^{6} \text { ) }\right. & 113 \pm 106 \\ \text { TMSC after washing }\left(\times 10^{6}\right) & 90 \pm 84 \\ \text { Estradiol level on hCG** day (pg/ml) } & 506 \pm 410 \\ \text { Dominant follicle count } & 1.5 \pm 0.8 \\ \text { Insemination time } & 33(15.9 \%) \\ \text { - 24 hours after hCG administration } & 173(83.2 \%) \\ \text { - 36 hours after hCG administration } & 35 / 206(16.8 \%) \\ \text { Clinical pregnancy rate per cycle } & \end{array}$

Note: Values are presented as mean \pm SD or number and percentage where applicable; *Total motile sperm count; **Human chorionic gonadotropin 
23.9\%, $p=0.04$ ) (Table 3). Estradiol level on hCG day, dominant follicle count, BMI, stimulation duration and previous pelvic surgery approached statistical significance $(p<0.01)$ in regression model fitting of IUI success (Table 4). The comparison of CPR according to dominant follicle count $=1(10.9 \%)$ and dominant follicle count $>1(27.3 \%)$ revealed out significant difference $(p=0.002)$. There was no significant difference between the CPR of women compared according to stimulation duration.

\section{DISCUSSION}

The results obtained from the present study revealed significantly higher CPR in COS/IUI cycles of patients with higher estradiol levels than $465 \mathrm{pg} / \mathrm{ml}$. A nd this study represented that the pregnancy possibility of women with two or three dominant follicle was significantly higher than the women with one dominant follicle. The overall CPR in the present study was $16.8 \%$, and this result was consistent with the IUI success rate of reported other studies. ${ }^{3,9,10}$ Ovarian stimulation with gonadotropins combined with IU I improves the probability of conception in unexplained infertility and male subfertility. ${ }^{11,12}$ Timing of insemination during periovulatory period is the major goal of treatment to provide sperm that are capable of fertilizing the oocyte. Scheduling IUI at different time points is one of the strategy to develop this goal. The investigators reported improved fecundity for double insemination performed 12 and 34 hours after hCG administration and timing insemination 60 hours after hCG administration were also reported. ${ }^{13}$ In our study we performed single insemination either 24 hours (to skip weekend) or 36 hours (during weekday) after hCG administration and there was no significant difference between the pregnancy rates of these two scheduling ( 12.1 vs $17.9 \%, p=0.41$ ).

In a retrospective study, the duration of infertility reported as a factor that have influence on conception rate. ${ }^{14}$ In our study, the infertility duration did not show a difference between couples according to conception. A nother factor associated with IUI success is the pelvic surgery that a history of corrective pelvic surgery is a significant risk factor for poor IUI outcome. ${ }^{15}$ In our study previous pelvic surgery showed minimal influence on IUI success $(O R=0.23, p<0.01)$. It is known that age is a major determinant of IU I success ${ }^{15}$ and in our study the mean age of the women was 29 years and there was no difference for age between women classified according to estradiol level on hCG day. Tomlinson et al reported the preovulatory follicle number one of the most predictive variable of IUI success with the chance of conceiving when only one follicle was produced was only $7.6 \%$, whereas with two follicles this chance increased to $26 \% .{ }^{14}$ In our study the CPR of women with two or three preovulatory follicle was significantly higher than of women with one dominant follicle (10.9 vs $27.3 \%, p<0.01)$.

Table 3: Comparison of main characteristics of couples according to estradiol level on hCG administration day

Characteristics
Female age (years)
Infertility duration $($ months)
Body mass index $\left(\mathrm{kg} / \mathrm{m}^{2}\right)$
Day $3 \mathrm{FSH}(\mathrm{mlU} / \mathrm{ml})$
Day $3 \mathrm{LH}(\mathrm{mlU} / \mathrm{ml})$
Day $3 \mathrm{E}_{2} *(\mathrm{pg} / \mathrm{ml})$
TMSC** $\left(\times 10^{6}\right)$
TMSC after washing $\left(\times 10^{6}\right)$
Total motility $(\%)$
Stimulation duration (days)
Dominant follicle count
Clinical pregnancy rate $(\%)$

$E_{2}<465 \mathrm{pg} / \mathrm{ml}(\mathrm{n}=113)$
$29 \pm 4.6$
$51.6 \pm 34.8$
$25.1 \pm 4.4$
$6.5 \pm 4.3$
$5.7 \pm 4.7$
$53.3 \pm 35.1$
$109.9 \pm 102.5$
$97.5 \pm 75.7$
$66.6 \pm 15$
$9.6 \pm 3.2$
$1.1 \pm 0.3$
12.4

$\begin{array}{cc}\mathrm{E}_{2}>465 \mathrm{pg} / \mathrm{ml}(\mathrm{n}=93) & p \text {-value } \\ 29.8 \pm 5.3 & 0.33 \\ 55 \pm 46.9 & 0.57 \\ 24 \pm 3.9 & 0.10 \\ 5.5 \pm 2.1 & 0.07 \\ 6.2 \pm 4.0 & 0.48 \\ 53.2 \pm 38.4 & 0.99 \\ 116.7 \pm 100.5 & 0.67 \\ 101.8 \pm 78.9 & 0.77 \\ 68.5 \pm 16.9 & 0.44 \\ 9.6 \pm 4.5 & 0.93 \\ 2.3 \pm 0.9 & <0.01 \\ 23.9 & 0.04\end{array}$

*Estradiol; **Total motile sperm count

\begin{tabular}{lccc}
\multicolumn{4}{c}{ Table 4: Regression analysis of factors that have influence on insemination success } \\
\hline Factors & p-value & $95 \% \mathrm{Cl}$ & OR \\
\hline E2 $_{2}$ level on hCG** day & $<0.01$ & $0.147-0.687$ & 0.31 \\
DFC & $<0.01$ & $0.070-0.212$ & 0.12 \\
Stimulation duration & $<0.01$ & $0.201-0.705$ & 0.37 \\
BMI\# & $<0.01$ & $0.113-0.259$ & 0.17 \\
Pelvic surgery & $<0.01$ & $0.156-0.346$ & 0.23 \\
TMSC & 0.23 & $0.225-1.443$ & 0.23 \\
TMSC after washing & $<0.01$ & $0.143-0.501$ & 0.26 \\
Insemination time & 0.12 & $0.134-1.270$ & 0.41 \\
\hline
\end{tabular}

*Estradiol; **Human chorionic gonadotrophin; "Dominant follicle count; \#"Body mass index; ${ }^{\S}$ Total motile sperm count 
It is difficult to determine male parameters that have influence on IUI success. For male subfertility IUI is a proven treatment modality with low success rate. ${ }^{16,17}$ Campana et al reported the pregnancy rate of couples with total motile sperm count $<1 \times 10^{6}(2.1 \%)$ lower than of couples $>1 \times 10^{6}(6.7 \%) .{ }^{18}$ A nother study reported lower pregnancy rate with motility $<20 \%$ in inseminate. ${ }^{19} \mathrm{~A}$ group of European investigators reported the number of inseminated spermatozoa as the only significant variable of insemination success. ${ }^{20} \mathrm{~A}$ study from Scandinavian population investigated total motile sperm count, $5 \times 10^{6}$ cut-off value, one of the six predictor of IUI outcome. ${ }^{17}$ It is difficult to determine a universal threshold for total motile sperm count or motility of inseminate. Each center should evaluate its results and define a threshold for their population and laboratory. ${ }^{9}$ In our study we found a minimal influence of total motile sperm count after washing on IUI success. The in vitro use of some substances (pentoxifylline and others) to stimulate sperm function has not generalized in IUI setting. ${ }^{21-23}$

This study had some limitations which should be mentioned. Firstly, our study population was consisted of unexplained infertility and male subfertility. This heterogenity might be excluded with recruiting the study population from only unexplained infertility. And secondly, it would have been much better if we had increased the study population.

\section{CONCLUSION}

IUI is a very useful and cost-effective treatment modality for some infertility etiologies. While female age, previous pelvic surgery and severe male factor have negative impact on IUI success, unexplained and anovulatory infertility have a favorable outcome. Serum estradiol level on the day of hCG administration will give insight to predict insemination outcome. Estradiol level $<465 \mathrm{pg} / \mathrm{ml}$ may indicate poor outcome in mild ovarian stimulation combined with insemination.

\section{ACKNOWLEDGMENT}

We thank to all staffs of our IV F C enter for their help during the study.

\section{REFERENCES}

1. Oehninger S. Place of ICSI in management of male infertility. Lanset 2001;357:2068-2069.

2. Allen NC, Herbert CM 3rd, Maxson WS, Rogers BJ, Diamond M P, W entz A C. Intrauterine insemination: a critical review. Fertil Steril 1985;44:569-580.

3. Ombelet W, Puttemans $P, B$ osmans E. Intrauterine insemination: a first-step procedure in the algorithm of male subfertility treatment. Hum Reprod 1995;10:90-102.
4. Goverde A J, M cD onnell J, V ermeiden J P, Schats R, Rutten FF, Schoemaker J . Intrauterine insemination or in-vitro fertilisation in idiopathic subfertility and male subfertility: a randomised trial and cost-effectiveness analysis. L ancet 2000;355:13-18.

5. Nuojua-Huttunen $S$, Tomas $C$, Bloigu R, Tuomivaara $L$, $M$ artikainen $\mathrm{H}$. Intrauterine insemination treatment in subfertility: an analysis of factors affecting outcome. Hum Reprod 1999;14: 698-703.

6. van Rumste $M M$, Custers IM, van der V een $F$, van W ely $M$, Evers J L, M ol BW. The influence of the number of follicles on pregnancy rates in intrauterine insemination with ovarian stimulation: a meta-analysis. Hum Reprod Update 2008;14: 563-570.

7. World Health Organization. Laboratory manual for the examination of human semen and semen-cervical mucus interaction. 3rd ed. Cambridge: Cambridge U niversity Press 1993;3-27.

8. Kruger TF, A costa AA, Simmons KF, Swanson RJ, M atta JF, Oehninger $S$. Predictive value of abnormal sperm morphology in in vitro fertilization. Fertil Steril 1998;49:112-117.

9. Duran HE, M orshedi M, Kruger T, O ehninger S. Intrauterine insemination: a systematic review on determinants of success. Hum Reprod U pdate 2002;8:373-384.

10. Berker B, Kahraman K, Taskin S, Sukur Y E, Sonmezer M, A tabekoglu CS. Recombinant FSH versus clomiphene citrate for ovarian stimulation in couples with unexplained infertility and male subfertility undergoing intrauterine insemination: a randomized trial. A rch Gynecol O bstet 2011;284:1561-1566.

11. Nulsen JC, W alsh S, Dumez S, M etzger D A. A randomized and longitudinal study of human menopausal gonadotropin with intrauterine insemination in the treatment of infertility. Obstet Gynecol 1993;82:780-786.

12. Guzick DS, Carson SA, Coutifaris C, Overstreet JW, FactorLitvak $P$, Steinkampf $M P$ et al. Efficacy of superovulation and intrauterine insemination in the treatment of infertility. National Cooperative Reproductive Medicine Network. N Engl J Med 1999;340:177-183.

13. Ragni G, Maggioni P, Guermandi E, Testa A, Baroni E, Colombo $M$, et al. Efficacy of double intrauterine insemination in controlled ovarian hyperstimulation cycles. Fertil Steril 1999;72:619-622.

14. Tomlinson M J, A missah-A rthur JB, Thompson KA, K asraie J L, $B$ entick $B$. Prognostic indicators for intrauterine insemination (IUI): statistical model for IUI success. Hum Reprod 1996;11: 1892-1896.

15. Hendin BN, Falcone T, Hallak J, Nel son DR, V emullapalli S, Goldberg J, et al. The effect of patient and semen characteristics on live birth rates following intrauterine insemination: a retrospective study. J A ssist Reprod Genet 2000;17:245-252.

16. Oehninger $S$, Franken $D, K$ ruger $T$. A pproaching the next millennium: how should we manage andrology diagnosis in the intracytoplasmic sperm injection era? Fertil Steril 1997;67: 434-436.

17. K halil MR, Rasmussen PE, Erb K, Laursen SB, Rex S, W estergaard LG. Homologous intrauterine insemination. An evaluation of prognostic factors based on a review of 2473 cycles. A cta Obstet Gynecol Scand 2001;80:74-81.

18. Campana A, Sakkas D, Stalberg A, Bianchi PG, Comtel, Pache T, et al. Intrauterine insemination: evaluation of the results according to the woman's age, sperm quality, total sperm count per insemination and life table analysis. Hum Reprod 1996;11: 732-736. 
19. Stone $B A, V$ argyas J $M$, Ringler $G E$, Stein $A L, M$ arrs $R P$. Determinants of the outcome of intrauterine insemination: analysis of outcomes of 9963 consecutive cycles. A m J Obstet Gynecol 1999;180:1522-1534.

20. van der Westerlaken $L A, N$ aaktgeboren $N$, Helmerhorst FM . Evaluation of pregnancy rates after intrauterine insemination according to indication, age, and sperm parameters. J Assist Reprod Genet 1998;15:359-364.

21. M orales $P$, L Lanos $M, Y$ ovich JL, Cummins J M, Vigil P. Pentoxifylline increases sperm penetration into zona-free hamster oocytes without increasing the acrosome reaction. A ndrologia 1993;25:359-362.

22. Nassar A, M ahony M, Blackmore $P$, M orshedi M, Ozgur K, O ehninger $S$. Increase of intracellular calcium is not a cause of pentoxifylline-induced hyperactivated motility or acrosome reaction in human sperm. Fertil Steril 1998;69:748-754.

23. B rown SE, Toner JP, Schnorr JA, W illiams SC, Gibbons WE, de Ziegler $D$, et al. V aginal misoprostol enhances intrauterine insemination. Hum Reprod 2001;16:96-101.

\section{ABOUT THE AUTHORS}

\section{Remzi Atilgan}

A ssistant Professor, D epartment of Obstetrics and Gynecology, Firat University H ospital, Elazig, Turkey

\section{Mustafa Ekinci}

Student, Department of IVF Center, Firat University Hospital Elazig, Turkey

\section{Ekrem Sapmaz}

Professor, D epartment of O bstetrics and Gynecology, Firat U niversity Hospital, Elazig, Turkey

\section{Zehra Sema Ozkan (Corresponding Author)}

A ssistant Professor, Department of Obstetrics and Gynecology In vitro Fertilization Center, FiratU niversity Hospital, Elazig, Turkey e-mail:zehrasema@yahoo.com 